\title{
Novel chlorambucil-conjugated anionic linear- globular PEG-based second-generation dendrimer: in vitro/in vivo improved anticancer activity
}

\author{
Artin Assadi' \\ Vahideh Sharifi Najafabadi' \\ Seyed Ataollah Sadat \\ Shandiz ${ }^{2}$ \\ Azadah Shayeq Boroujeni' \\ Sepehr Ashrafi' \\ Ali Zaman Vaziri' \\ Seyedeh Masoumeh \\ Ghoreishi' \\ Mohammad Reza \\ Aghasadeghi ${ }^{3}$ \\ Seyed Esmaeil Sadat \\ Ebrahimi ${ }^{4}$ \\ Morteza Pirali-Hamedani ${ }^{4}$ \\ Mehdi Shafiee Ardestani' \\ 'Department of Radiopharmacy, \\ Faculty of Pharmacy, Tehran \\ University of Medical Sciences, \\ ${ }^{2}$ Young Researchers and Elite Club, \\ East Tehran Branch, Islamic Azad \\ University, ${ }^{3}$ Department of Hepatitis \\ and AIDS, Pasteur Institute of Iran, \\ ${ }^{4}$ Department of Medicinal Chemistry, \\ Faculty of Pharmacy, Tehran University \\ of Medical Sciences, Tehran, Iran
}

\author{
This article was published in the following Dove Press journal: \\ OncoTargets and Therapy \\ 7 September 2016 \\ Number of times this article has been viewed
}

\begin{abstract}
Evaluating the efficacy of anticancer drugs is an evolving and research-oriented issue. The objective of this study was to reduce the insolubility of chlorambucil (CBL) in water and improve the anticancer activity of CBL in vitro and in vivo through the conjugation of CBL with anionic linear-globular dendrimer (second generation, G2). In the current study, the anticancer activity among three groups that include CBL, CBL-G2 dendrimer, and control was measured in vitro and in vivo. In vitro studies showed that G2 anionic linear-globular polyethylene-glycolbased dendrimer, which conjugated to the CBL exterior through an ester linkage, was able to significantly improve the treatment efficacy over clinical CBL alone with respect to proliferation assay, 2,3-bis-(2-methoxy-4-nitro-5-sulfophenyl)-2H-tetrazolium-5-carboxanilide; half maximal inhibitory concentration $\left(\mathrm{IC}_{50}\right.$ ) was calculated to be $141 \mu \mathrm{g} / \mathrm{mL}$ for $\mathrm{CBL}$ alone and $27.7 \mu \mathrm{g} / \mathrm{mL}$ for $\mathrm{CBL}-\mathrm{G} 2$ dendrimer; $P<0.05$. In addition, $\mathrm{CBL}-\mathrm{G} 2$ dendrimer conjugate forestalled the growth of MCF-7 cancerous cells in addition to enhancing the number of apoptotic and necrotic cells as demonstrated by an annexin V-fluorescein isothiocyanate assay. CBL-G2 dendrimer conjugate was able to checkmate antiapoptotic Bcl-2 expression and Bcl-2/Bax ratio in a large scale compared with the control group and $\mathrm{CBL}$ alone $(P<0.005)$. In vivo studies showed that tumor treatment by $\mathrm{CBL}-\mathrm{G} 2$ dendrimer conjugate outstrips the efficacy of treatment compared with $\mathrm{CBL}$ alone. The evaluation was based on reduction in tumor volume and tumor growth inhibition of murine 4T1 mammary tumor cells. Tumor volume of $140 \% \pm 8 \%$ was measured in the treatment with $\mathrm{CBL}-\mathrm{G} 2$ dendrimer, whereas $152 \% \pm 13.5 \%$ was calculated in the treatment with free CBL $(P<0.05)$. However, there were no significant differences in histological assay among the three groups. In conclusion, tumor growth suppression potential of CBL-G2 dendrimer, which was assessed in both in vitro and in vivo experiments, has provided empirical evidence to buttress the fact that this compound could be considered for functional cancer treatment with low side effects.
\end{abstract}

Keywords: anionic linear-globular dendrimer, G2, chlorambucil, CBL, in vitro cytotoxicity, in vivo efficacy

\section{Introduction}

For years, cancer chemotherapies have been dominated by alkylating agents whose satisfactory results in many cases of cancer treatment have made the nitrogen mustard, chlorambucil (CBL), unrivaled as the main medication for fighting cancer. To target chronic lymphocytic blood cancer, CBL (given orally) is known to be the strongest weapon. It is equally important in the treatment of malignancies, ie, certain types of non-Hodgkin lymphoma, trophoblastic neoplasms, and ovarian cancer. This combination class consisting of alkylation of N7 atoms of guanine or adenine and N3 of
Correspondence: Mehdi Shafiee Ardestani Department of Radiopharmacy, Faculty of Pharmacy, Tehran University of Medical Sciences, 16th Azar Street, Enghelab Square, Tehran I417466191, Iran Tel/fax +98 2I 66959098 Email shafieeardestani@tums.ac.ir 
adenine in double-helical DNA has proven its essentiality in preventing cell growth and spread. ${ }^{1}$ Being recognized as water insoluble, CBL has been used as a model to assess the controlled drug delivery features of copolymer aggregates, since enhancing the solubility of highly hydrophobic drugs is achievable only through improvement of their therapeutic efficiency. In addition, monitoring drug release by fluorescence measurements is made possible by CBL indication of fluorescence emission. ${ }^{2}$ Admittedly, however, administering CBL might be a reason for the occurrence of side effects, such as nausea, vomiting, bone marrow suppression, anemia, immune suppression, and increased risk of infection. ${ }^{3}$ In addition, the creation of poorly water-soluble drugs has been the main subject of study, as improving bioavailability after oral or parenteral delivery is of the greatest essence. Previous creations rely on surfactant micelles, micro- or nanoparticles, solid spreading out, complexation with cyclodextrin, and mixing with co-solvents. ${ }^{4}$

Dendrimers are hyperbranched, monodisperse, threedimensional macromolecules, defining the molecular weight and host-guest entrapment features. Having control of measurable features such as size, shape, and location of functional groups and possession of various attributes of small organic molecules and polymers, they achieve special physical and chemical features, ${ }^{5}$ and not surprisingly, many polyethylene glycol (PEG)ylated dendrimeric systems have been a base for trial and error since they are regarded as the best prospective drug delivery agents because of their water-soluble dendritic unimolecular micelle. ${ }^{6}$ The popular polymer that is referred to as PEG, and this is easily proven true by searching the literature, has proven to be a valuable asset in daily or industrial applications along with many biomedical drug delivery systems. Also, one can evaluate its success based on countless pharmaceutical products that have been approved by the US Food and Drug Administration (FDA) and the European Medicines Agency every day throughout the past 2 decades. In this study, we applied novel anionic linear-globular PEG-based dendrimer (second generation, G2) conjugated to CBL. PEG can be rather easily degraded in biological conditions compared to polymers with a carbon backbone. Although PEG on its own seems to be immunologically harmless, the same cannot be confirmed about the molecule to which PEG is paired. For we know the degree of PEGylation is a significant factor in determining the immunogenicity of PEG.

Undoubtedly, PEG, as a nonionic hydrophilic polymer, could sterically stabilize conjugates. Stability can be explained by the protection provided to the active sites by the PEG chains. Hydrophilic PEG chains at the surface of polymers prevent aggregation of non conjugate particle exterior groups. This characteristic allows PEG to be considered as a polymer to conjugate with biomedical particles. The molar mass, as well as the polydispersity of the polymer, as shown in many applications, still has the unparalleled significance regarding biocompatibility and stealth behavior. The molar mass of PEG used in different pharmaceutical and medical applications ranges from $400 \mathrm{Da}$ to about $50 \mathrm{kDa}^{7}$ Citric acid-PEG-citric acid surround and block dendrimers as biocompatible compounds containing first generation (G1), G2, and third generation (G3) in the drugdelivery systems. As mentioned earlier, the dendrimer used in this study is based on G2 to conjugate with CBL. Some of the smaller molecules and drugs are also enclosed with the above-synthesized dendrimers. The guest molecules, which are hydrophobic when enclosed in the appropriate environment of dendrimers, become soluble in an aqueous solution. ${ }^{8}$ The evaluation of the cytotoxicity of a novel G3 PAMAM-NH2 dendrimer-CBL combination employing a 2,3-bis-(2-methoxy-4-nitro-5-sulfophenyl)-2 $H$-tetrazolium5 -carboxanilide (XTT) test and inhibition of [3H] thymidine incorporation including DNA in both MDA-MB-231 and MCF- 7 breast cancer cells, has affirmed that the combination was a stronger antiproliferative agent than CBL alone. In addition, it was observed that in terms of collagen biosynthesis cessation, dendrimer-CBL combination is in a more active status than CBL alone. ${ }^{9}$

This study aims to represent a new G2 anionic linearglobular dendrimer for CBL delivery applications. We were particularly focused on the production of well-defined stable nanoparticles via a sustainable and versatile technique, which would also accommodate a variety of therapeutic agents. Our choice of nano-sized anionic linear-globular dendrimer was greatly influenced by the global release of numerous hydrophilic drugs in addition to the popularity of aqueousbased nanoparticles compared with hydrophobic alternatives. Moreover, we figured out a stealth behavior favoring the properties of hydrophilic surface coatings. The information was obtained via atomic force microscopy, proton nuclear magnetic resonance (HNMR), Fourier transform infrared spectroscopy (FTIR), liquid chromatography-mass spectrometry (LC/MS, or alternatively high-performance LC-MS), and zeta potential. In vitro and in vivo cytotoxicity of CBL-G2 dendrimer in MCF-7 breast cancer and mouse 4T1 breast tumor model, respectively, was examined using growth inhibition assays of XTT and flow cytometry. The pairing abilities of CBL-G2 dendrimer conjugate and CBL 
alone to emit proapoptotic signals were assessed by regulation in $\mathrm{Bax} / \mathrm{Bcl}-2$ gene expression ratio.

\section{Materials and methods Determination of CBL-G2 dendrimer conjugate}

FTIR (NEXUS 870; Thermo Fisher Scientific, Waltham, MA, USA) was used to confirm the conjugation of CBL with G2. The structure and distribution size of the conjugation of CBL-G2 dendrimer were confirmed by Model AP-2001 (Thermo Microscopes, Waltham, MA, USA) and dynamic light scattering (Zetasizer Nano ZS; Malvern Instruments, Malvern, UK).

In order to investigate the molecular structure of the CBL-G2 dendrimer conjugate, LC/MS analyses were provided by Agilent 6410 Triple Quadrupole LC/MS.

Then, $2 \mathrm{mg}$ of CBL-G2 dendrimer conjugate was dissolved in $\mathrm{D}_{2} \mathrm{O}$, and after a gentle stirring at room temperature it was kept in HNMR equipment (Bruker Corporation, Billerica, MA, USA) and the conjugate HNMR spectrum was obtained.

\section{Chemical synthesis of the CBL-G2 dendrimer conjugates}

The procedure to make $\mathrm{G} 2$ dendrimer was adapted from earlier reports in the literature, but with moderate variations. ${ }^{10}$ In detail, PEG 600 (4 mL) was dissolved with dimethyl sulfoxide (DMSO) solution ( $5 \mathrm{~mL}$ ) (to speed up the solubility process and increase the reaction rate) and $10 \mathrm{mg}$ of $N, N^{\prime}$-dicyclohexylcarbodiimide (DCC; as an activator) was added into the solution under vigorous magnetic stirring at room temperature for 15 minutes. After 15 minutes, citric acid (1 g) (as a linker) was slowly added into the solution while stirring. After a while, $10 \mathrm{mg}$ of DCC and $2 \mathrm{~g}$ of citric acid were also added to the mixture under magnetic stirring for 4 days at room temperature. After 4 days, since DCC was replaced with citric acid, the color of the solution changed to orange. The reaction was ended with adding water after filtration; then, the solution of G1 dendrimer was obtained. The crude product was subjected to a lyophilization process. After that, the product was mixed with DMSO $(5 \mathrm{~mL}), \mathrm{CBL}$ (0.05 g), 1-ethyl-3-(3-dimethylaminopropyl carbodiimide) (as an activator; $10 \mathrm{mg}$ ), and calcium chloride $\left(\mathrm{CaCl}_{2} ; 10 \mathrm{mg}\right.$ ) under vigorous magnetic stirring at room temperature for 20 minutes. The added 1-ethyl-3-(3-dimethylaminopropyl carbodiimide) improved the reaction efficiency between carboxyl groups of both $\mathrm{CBL}$ and dendrimer. Water, as a product of the reaction like PEG, has a nucleophilic group and competes with PEG. Thus, water should be removed from the solution; therefore, $\mathrm{CaCl}_{2}$ was used to function as a water remover. In addition, $\mathrm{CaCl}_{2}$ contributes a basic nature to the solution, which can facilitate conjugation. The reaction blend was agitated ceaselessly for 1 week at room temperature in the dark. After 1 week, it was dialyzed against an excess amount of water using membrane (pore size of dialysis bag was 500-1,000 Da) for 24 hours to separate free CBL, DMSO, and unreacted DCC. Finally, after lyophilization, a greenish doughy product was obtained $(1.3 \mathrm{mg} / \mathrm{mL}$, $80 \%$ yield).

The drug-loading capacity (DLC) was calculated according to the following formula:

$$
\text { DLC }(\%)=\frac{\text { Weight of drug used }}{\text { Weight of polymer drug used }} \times 100 \%
$$

\section{In vitro cell culture}

The human breast cancer cell line (MCF-7) obtained from Pasteur Institute (Tehran, Iran) was cultured at $37^{\circ} \mathrm{C}$ in $5 \%$ $\mathrm{CO}_{2}$ under standard cell culture media that included RPMI 1640. The cell culture medium was supplemented with $10 \%$ fetal bovine serum and 1\% penicillin/streptomycin. This study was approved by the ethical committee of Tehran University of the Medical Science Council.

\section{In vitro apoptosis/necrosis assay}

To determine apoptosis, an Annexin V-propidium iodide staining kit used according to the manufacturer's instruction was applied. For the cell viability test, the MCF7 cells (5,000 cells/well) were incubated with $\mathrm{CBL}-\mathrm{G} 2$ dendrimer $(130 \mu \mathrm{L})$ and $\mathrm{CBL}$ alone $(100 \mu \mathrm{L})$ in a 24 -well microplate for 96 hours, with untreated cells as a positive control. Each concentration was tested in duplicate.

\section{Analysis of apoptosis-related gene expression}

To investigate the mitochondrial apoptotic events, changes in the levels of Bax and Bcl-2 (glyceraldehyde 3-phosphate dehydrogenase [GAPDH] served as intrinsic control) were determined. A SYBR Green real-time polymerase chain reaction (PCR) was performed on cDNA extracted from the cell after the treatment with CBL-G2 dendrimer and CBL alone. The expression of target gene was quantified with SYBR Green PCR Master Mix using an ABI 7300 Real-Time PCR System (Thermo Fisher Scientific). The synthesis of cDNA was carried out in the thermal cycler at $50^{\circ} \mathrm{C}$ in 15 minutes. Denaturation of DNA was accomplished by heating at $95^{\circ} \mathrm{C}$ for 10 minutes, followed by 40 cycles of annealing and 
expansion of the template at $60^{\circ} \mathrm{C}$ for 45 seconds. Primers were designed using Primer Express Software, v.3.0 (Thermo Fisher Scientific). Primer specificity was tested using BLAST program (http://www.ncbi.nlm.nih.gov/blast). The values acquired for the target gene expression were normalized to GAPDH and analyzed by the relative gene expression $-\Delta \Delta \mathrm{Ct}$ method, where $\Delta \Delta \mathrm{Ct}=\mathrm{mCt}$ target $-\mathrm{mCt}$ GAPDH (treated sample) - mCt target - mCt GAPDH (untreated sample). Eventually, Bcl-2/GAPDH and Bax gene expression ratios were calculated utilizing the ratio formula (ratio $=2^{-\Delta \Delta C t}$ ).

\section{In vivo efficacy}

Exploring in vivo antitumor efficacy was carried out on murine 4T1 mammary tumor cells that were acquired from the Pasteur Institute of Iran. Cells were cultured and preserved at $37^{\circ} \mathrm{C}$ in a humidified incubator with $5 \% \mathrm{CO}_{2}$. The cell culture medium was composed of Dulbecco's Modified Eagle's Medium (DMEM), 10\% fetal bovine serum, $2 \mathrm{mM}$ L-glutamine, $100 \mathrm{U} / \mathrm{mL}$ penicillin, and $100 \mu \mathrm{g} / \mathrm{mL}$ streptomycin. Fifteen female BALB/c mice (20 2 g, 6-8 weeks old) were acquired from the Pasteur Institute of Iran and chosen for the tumor model. In this study, BALB/c mice were divided into three groups (five mice for each group, including those who receive treatment with $\mathrm{CBL}$, and $\mathrm{CBL}-\mathrm{G} 2$ dendrimer, and also the untreated group) and kept in a sanitary condition with the 12-hour light/dark cycle at room temperature $\left(23^{\circ} \mathrm{C} \pm 2^{\circ} \mathrm{C}\right)$. The animal study was conducted in line with national Animal Care regulations and approved by the Animal Experiments Ethical Committee and the ethical committee of Tehran University of Medical Science Council. During tumor implantation, the mice were anesthetized by exposure to $1 \%-3 \%$ isoflurane $4 \mathrm{~T} 1$ tumor cells that were suspended at a density of $2 \times 10^{5}$ cells $/ \mathrm{mL}$ in DMEM cell culture medium. To establish a breast cancer $4 \mathrm{~T} 1$ model, the cell suspension $(50 \mu \mathrm{L} /$ mouse $)$ was subcutaneously inoculated into the back of three groups of female BALB/c mice. Tumor size was estimated using a caliper (length $\times$ width $\times$ height). One week was required for solid tumors to reach a range of $50 \mathrm{~mm}^{3}$ to $100 \mathrm{~mm}^{3}$. Receiving nonidentical treatment, tumor-carriage mice were randomly divided into three groups being injected via tail vein once. The injection was performed with saline (control), CBL (10 mg of CBL per $\mathrm{kg}$ of mouse weight), and CBL-G2 dendrimer $(1.4 \mathrm{mg} / \mathrm{kg}$ of mouse weight) in a final volume of $10 \mathrm{~mL}$. Tumor sizes and mouse body weights were calculated every 5 days. Tumor volumes were normalized to $100 \%$ at day 0 and calculated using the following formula: ${ }^{11,12}$

$$
V\left(\mathrm{~mm}^{3}\right)=\frac{1}{2} \text { length }(\mathrm{mm}) \times \text { width }\left(\mathrm{mm}^{2}\right)
$$

On day 10, all animals were euthanized. Tumors were excised to calculate tumor growth inhibition (TGI), studied to evaluate apoptosis in the tumors, and fixed for histological examination. TGI was measured as: ${ }^{12}$

$$
\text { TGI }=\left(1-\frac{\text { Mean tumor weight of treatment group }}{\text { Mean tumor weight of control group }}\right) \times 100 \%
$$

\section{Histological assay}

The paired tumor and nontumor areas of each tumor tissue from the samples were fixed in 10\% formaldehyde, passaged, and embedded in paraffin. Paraffin blocks were prepared for staining after being cut into slices with 3-5 mm thickness. For each case, five slices were prepared for staining with hematoxylin and eosin. ${ }^{13}$

\section{Statistical analysis}

Statistical data analyses were performed using Prism and Excel software. For quantitative data analysis, paired $t$-test and one-way analysis of variance (ANOVA) in the case of cluster comparison were applied.

\section{Results}

\section{Results of determination of CBL-G2 dendrimer conjugate} The results of FTIR and HNMR

Figure 1 shows the FTIR spectrum related to CBL-G2 dendrimer conjugation. The peak $1,022 \mathrm{~cm}^{-1}$ is related to the $\mathrm{C}-\mathrm{O}$ group in ester-ether linkage between two molecules. Moreover, the peak $1,722 \mathrm{~cm}^{-1}$ in $\mathrm{C}=\mathrm{O}$ groups shows an ester linkage,

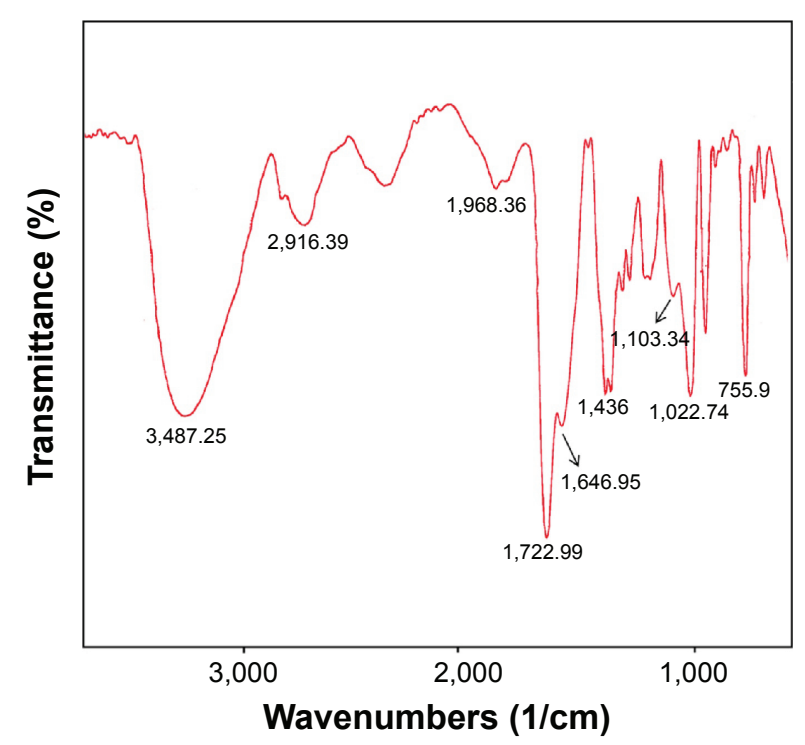

Figure I FTIR spectrum related to CBL-G2 dendrimer conjugation. Abbreviations: $\mathrm{CBL}$, chlorambucil; FTIR, Fourier transform infrared spectroscopy. 
indicating the conjugation of CBL to $\mathrm{G} 2$ through the ester linkage. The peak $1,643 \mathrm{~cm}^{-1}$ is related to the ring $\mathrm{C}-\mathrm{C}$ asymmetric stretching existing in the $\mathrm{CBL}$ aromatic ring. The peak $3,487 \mathrm{~cm}^{-1}$ shows $\mathrm{N}-\mathrm{H}$ stretches of amines related to CBL.

In general, in order to support the structure of CBL conjugated into dendrimer, it suffices to show the presence of aromatic regions and the twofold bands of CBL molecule beside the peaks of PEG and citric acid structures.

Figure 2 shows the HNMR spectrum related to $\mathrm{CBL}-\mathrm{G} 2$ dendrimer conjugation. As is clear in the spectrum figure, the doublet peaks related to the A-B system in citric acid can be observed at the region of 2.5-2.7 ppm and the strong peak of the PEG structure (CH2-CH2-O) can be observed at the region of 3.4-3.6 ppm beside a small curve observed at the region of 5.5 indicating the $\mathrm{PEG}$ structure $(\mathrm{CO}-\mathrm{O}-\mathrm{CH} 2-)$; in general showing the presence of $\mathrm{G} 2$ dendrimer in the molecule structure. In addition, the appearance of strong peaks at the regions of 6.1-7.6 ppm confirms the presence of the twofold band and aromatic regions of CBL compound in the structure of the nano-conjugated molecule. Therefore, in the nano-CBL spectrum, the main peaks supporting the presence of the two molecules of G2 dendrimer and CBL are well observed.

\section{The results of LC/MS}

For a precise confirmation of CBL conjugation to dendrimer, LC/MS was performed (Figure 3). Compared with the intact dendrimer, the different fragmentation patterns in the CBL-G2 dendrimer permitted us to confirm the formed conjugate.

\section{Size and zeta potential distribution}

The molecular size, charge, and morphology have significant change following the $\mathrm{CBL}-\mathrm{G} 2$ dendrimer conjugation. An enlargement in the size/polydisparity and a reduction (negative charge) in the zeta potential were observed in the conjugates as compared with the dendrimer. The slightly negative charges may derive from the carboxyl groups in both CBL and G2 moieties being conjugated (Figures 4 and 5).

The same confirming evidence was obtained by atomic force microscopy that showed roughly spherical particles (without sonication) (Figure 6).

\section{In vitro apoptosis necrosis assay}

The results of XTT assay, for CBL at the concentration of $2.5 \mu \mathrm{g} / \mathrm{mL}, 25 \mu \mathrm{g} / \mathrm{mL}$, and $130 \mu \mathrm{g} / \mathrm{mL}$ are shown (Figure 7). The results of XTT assay for CBL-G2 dendrimer is determined at the same concentrations (Figure 8). As is obvious, increasing the concentration, both of the CBL and CBL-G2 dendrimer, leads to decreasing cell viability. Significant statistical differences can be seen between control and $2.5 \mu \mathrm{g} / \mathrm{mL}, 25 \mu \mathrm{g} / \mathrm{mL}$, and $130 \mu \mathrm{g} / \mathrm{mL}$ of $\mathrm{CBL}$ and CBL-G2 dendrimer $(P<0.006)$. A significant difference $(P<0.05)$ was observed between the $10 \mu \mathrm{g}$ of $\mathrm{CBL}$ and the dose of CBL-G2 dendrimer conjugate (Figure 9). When it came to comparison, significant deference was attained (half maximal inhibitory concentration $\left[\mathrm{IC}_{50}\right]$ measurement between $\mathrm{CBL}$ and $\mathrm{CBL}-\mathrm{G} 2$ dendrimer was calculated to

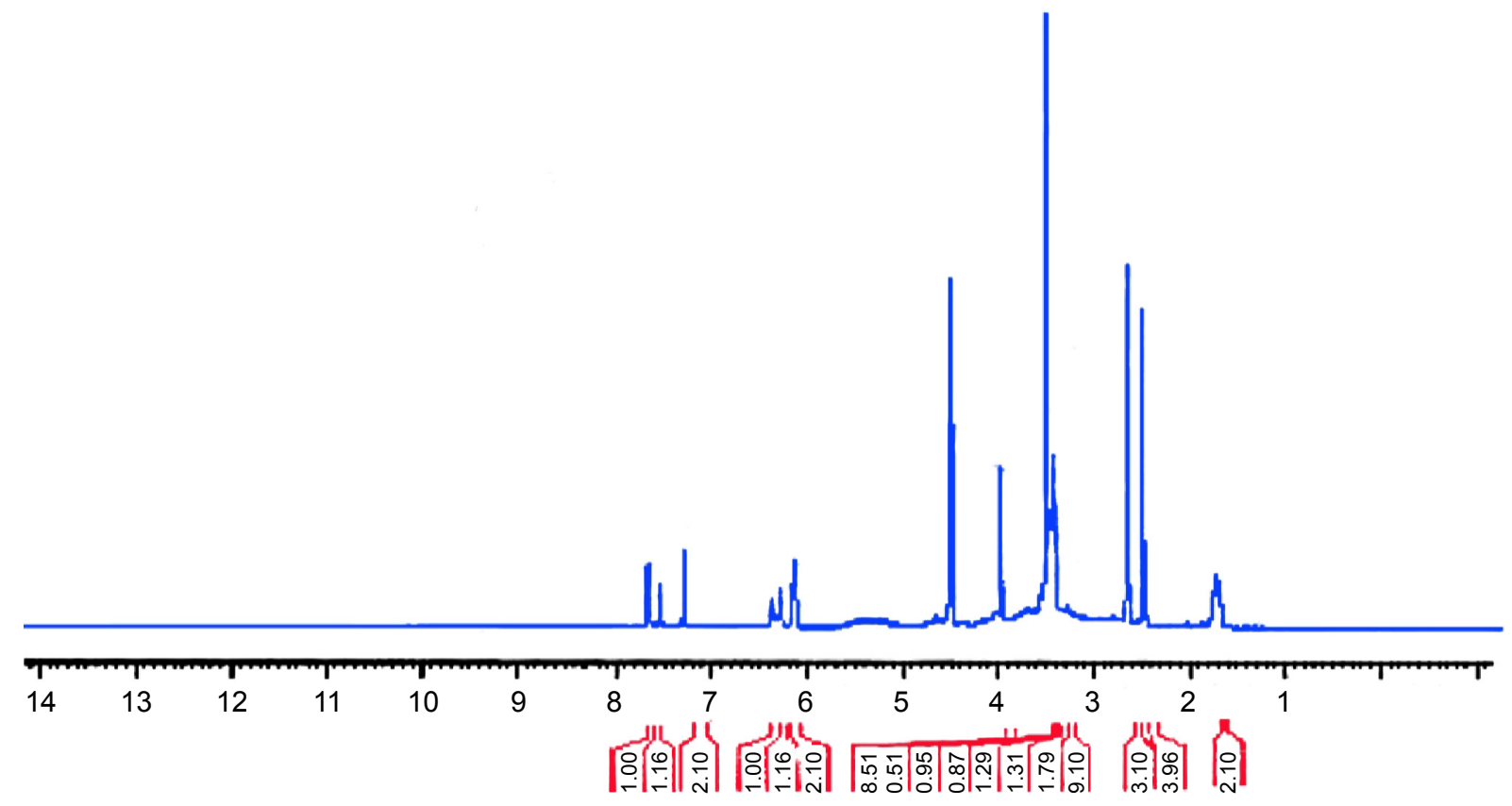

Figure 2 HNMR spectrum related to CBL-G2 dendrimer conjugation.

Abbreviations: $\mathrm{CBL}$, chlorambucil; HNMR, proton nuclear magnetic resonance. 


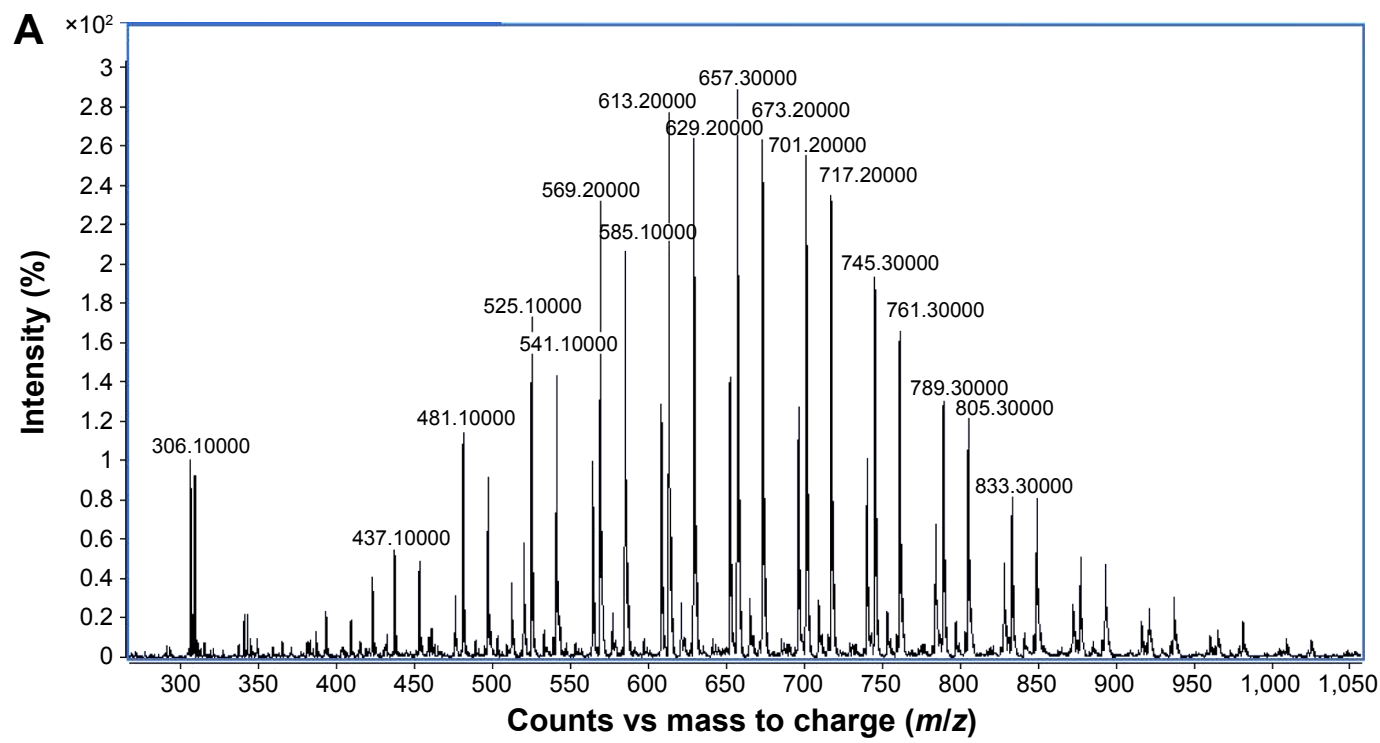

B

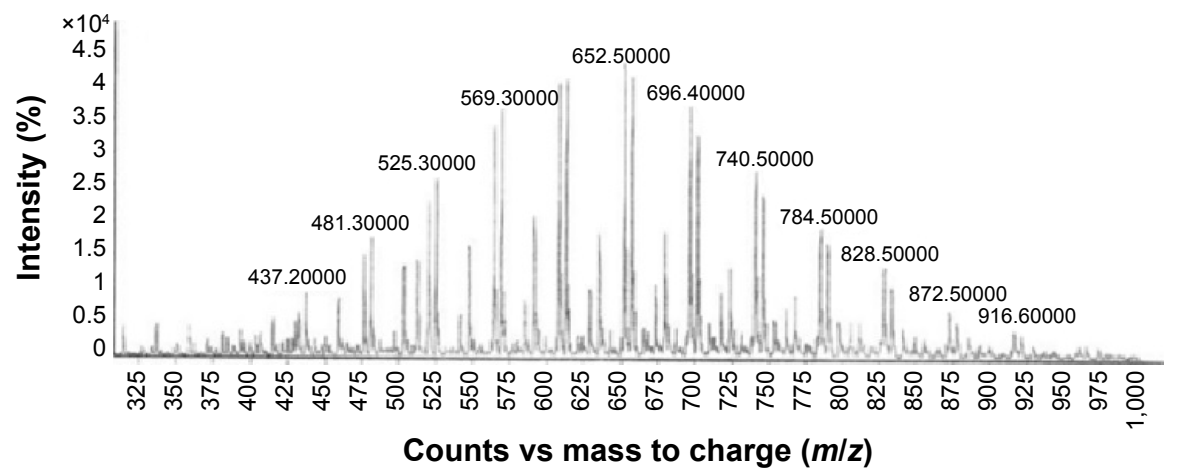

Figure $3 \mathrm{CBL}$ conjugation to dendrimer, obtained by LC/MS, (A) in comparison with intact $\mathrm{G} 2$ dendrimer (B). Abbreviations: CBL, chlorambucil; LC, liquid chromatography; MS, mass spectrometry.
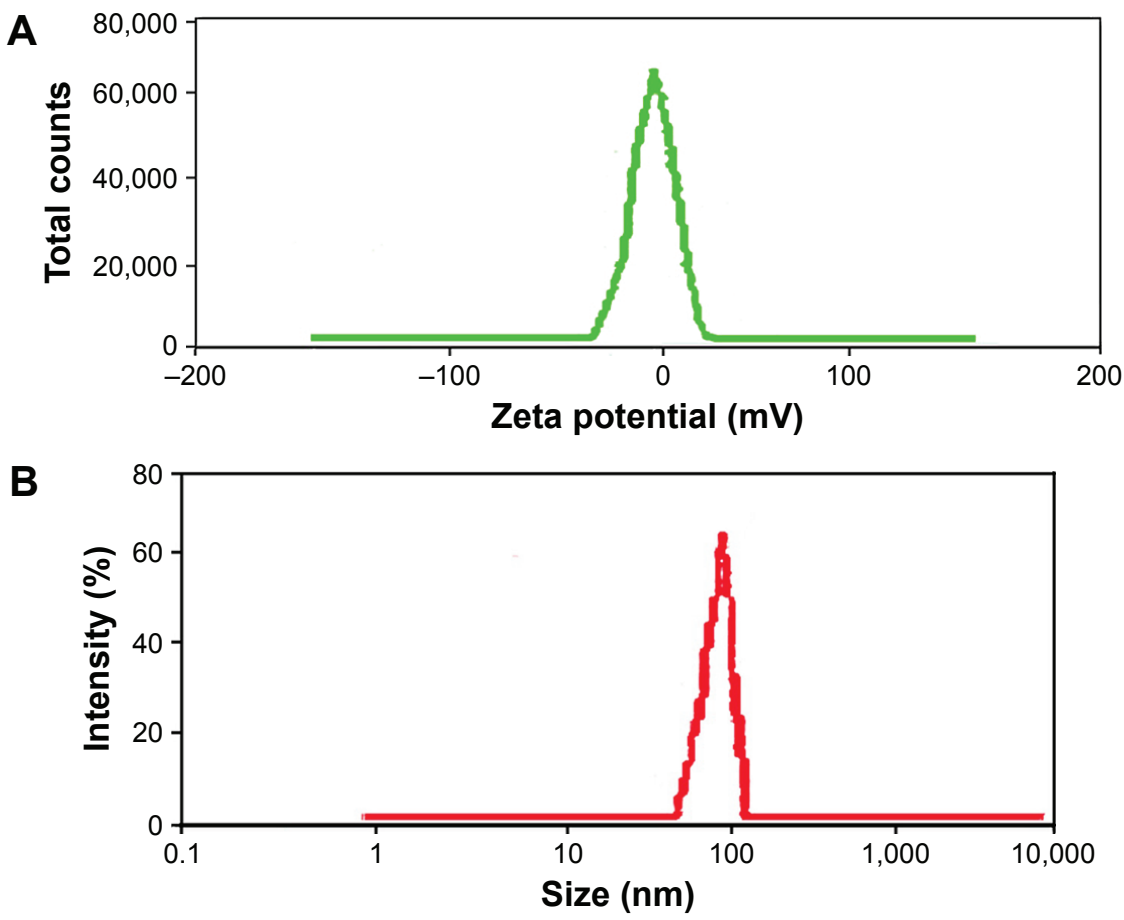

Figure 4 Size distribution and zeta potential of G2.

Note: (A), Zeta potential distribution; (B), size distribution of $G 2$. 

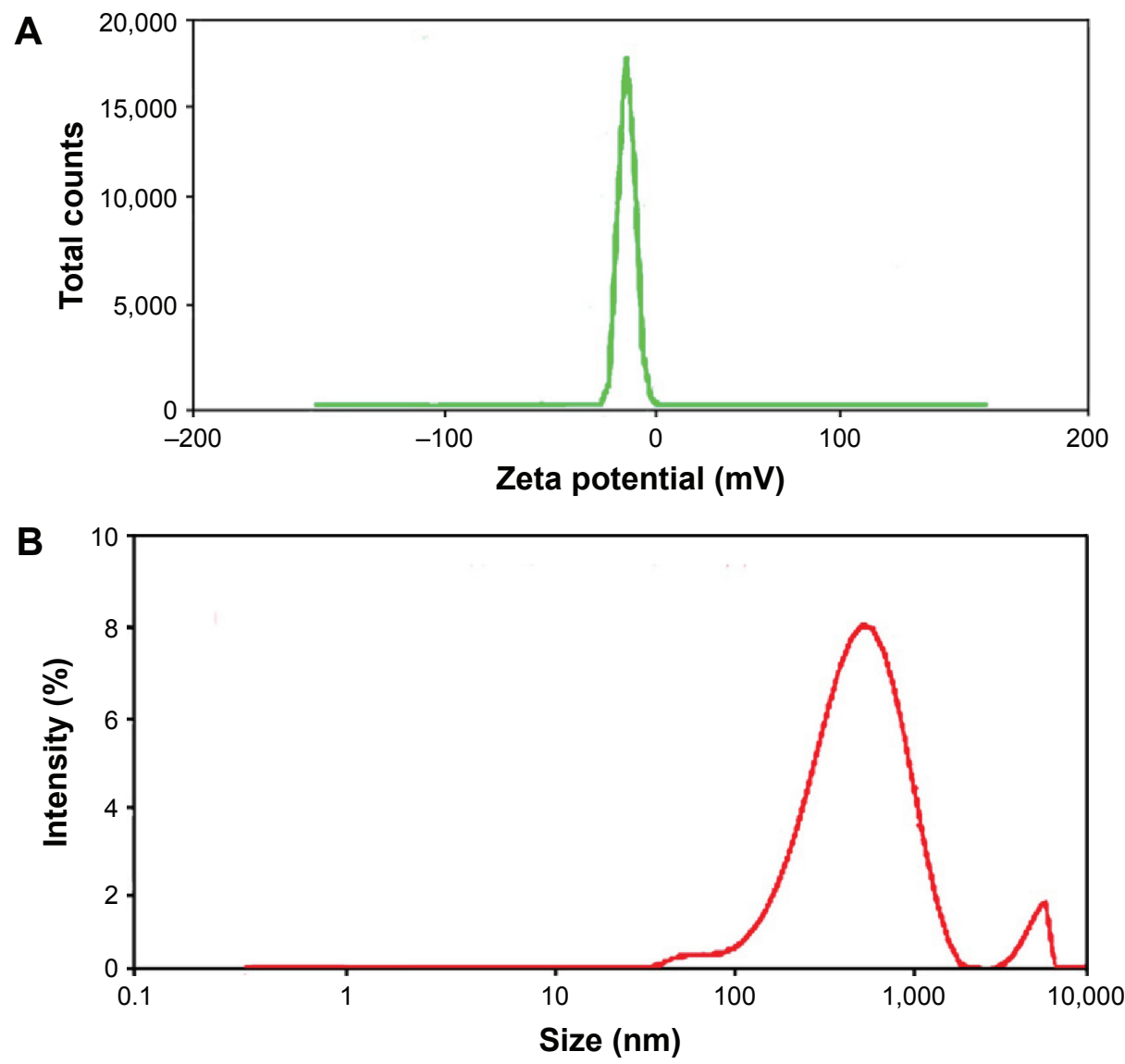

Figure 5 Size distribution and zeta potential of $C B L-G 2$ dendrimer. Note: (A), Zeta potential distribution; (B), size distribution of $G 2$.

Abbreviation: $\mathrm{CBL}$, chlorambucil.

be $141 \mu \mathrm{g} / \mathrm{mL}$ for $\mathrm{CBL}$ alone and $27.7 \mu \mathrm{g} / \mathrm{mL}$ for CBL-G2 dendrimer). The same conforming evidence was observed using a flow cytometry assay (Figure 10).

\section{Analysis of apoptosis-related gene expression}

In this study, a marked decrease was observed in the expression level of Bcl-2, leading to induction of apoptosis after 24-hour treatment with both $\mathrm{CBL}$ and $\mathrm{CBL}-\mathrm{G} 2$ dendrimer. This significant reduction was accompanied by a decrease in mRNA expression of Bax using $\mathrm{CBL}-\mathrm{G} 2$ dendrimer. We did not show any significant change in the mRNA expression of Bax gene upon treatment with CBL. A significant difference was observed among the control, $\mathrm{CBL}$, and CBL-G2 dendrimer in the expression levels of both Bax and Bcl-2 genes $(P<0.005$; Figure 11).
A

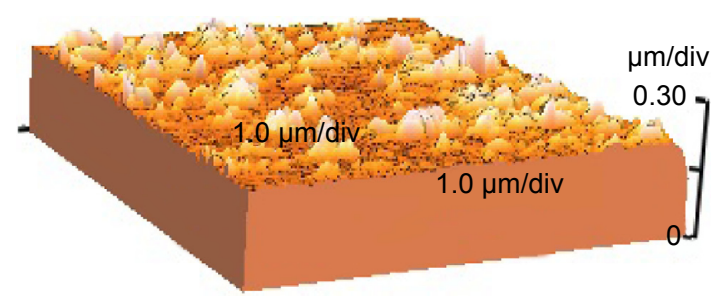

B

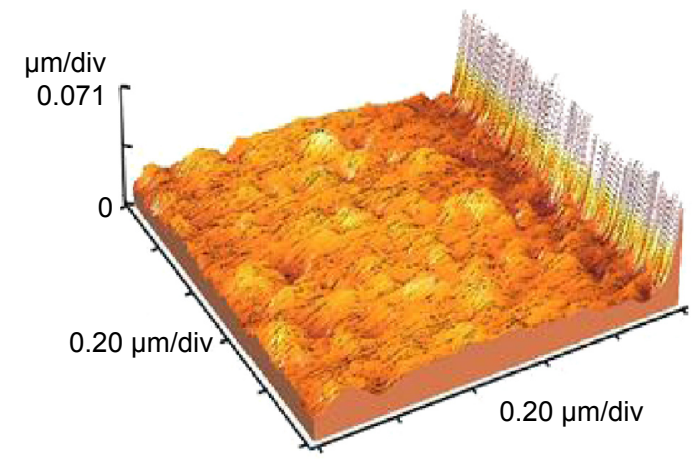

Figure 6 3D AFM image of CBL-G2 dendrimer (A) in comparison with intact $G 2$ dendrimer (B).

Abbreviations: AFM, atomic force microscopy; CBL, chlorambucil; 3D, three-dimensional. 


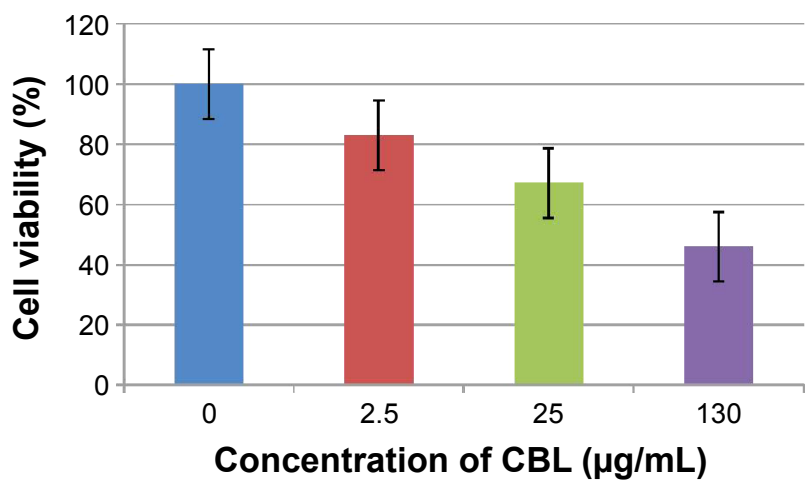

Figure 7 Results of XTT assay on MCF-7 cells, as percentage cell viability at different concentrations using $\mathrm{CBL}$.

Abbreviations: CBL, chlorambucil; XTT,2,3-bis-(2-methoxy-4-nitro-5-sulfophenyl)$2 \mathrm{H}$-tetrazolium-5-carboxanilide.

\section{In vivo efficacy}

This study demonstrated the superior therapeutic effect of CBL-G2 dendrimer on TGI compared with free CBL (Figure 12A and B). TGI was calculated as 13\% for CBL-G2 dendrimer, while it was $6 \%$ for free CBL. On the other hand the CBL-G2 dendrimer conjugate resulted in higher anticancer efficiency. Tumor volume of $140 \% \pm 8 \%$ was measured for the treatment with CBL-G2 dendrimer, whereas $152 \% \pm 13.5 \%$ was calculated for the treatment with free CBL in murine 4T1 mammary tumor cells at day 10. As a result, anticancer efficacy was significantly evidenced by the treatment with CBL-G2 dendrimer compared with either the CBL-treated group or saline control $(P<0.01$ versus saline, $P<0.05$ versus free $\mathrm{CBL}$ ). Neither mortality nor perceptible body weight loss was seen in the mice treated with $\mathrm{CBL}-\mathrm{G} 2$ dendrimer and free CBL compared with untreated control (Figure 13).

\section{Histological assay}

Slides showed that tumoral mass arrangement in sheets is composed of tumoral cells with high nuclear/cytoplasmic

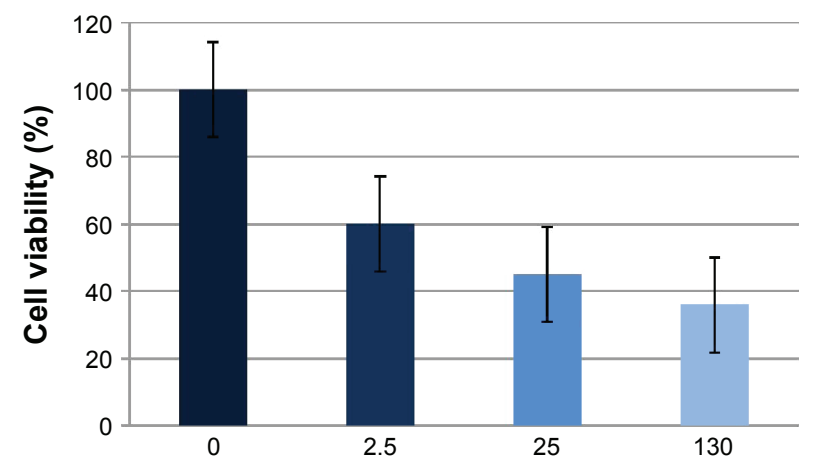

Concentration of CBL-G2 dendrimer $(\mu \mathrm{g} / \mathrm{mL})$

Figure 8 Results of XTT assay on MCF-7 cells, as percentage cell viability at different concentrations using $\mathrm{CBL}-\mathrm{G} 2$ dendrimer.

Abbreviations: CBL, chlorambucil;XTT,2,3-bis-(2-methoxy-4-nitro-5-sulfophenyl)$2 \mathrm{H}$-tetrazolium-5-carboxanilide.

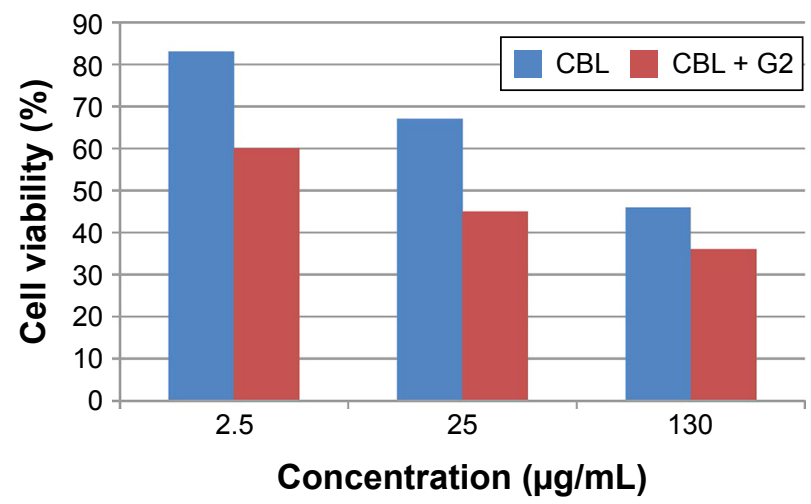

Figure 9 Results of XTT assay on MCF-7 cells, as percentage cell viability at different concentrations, compared using $\mathrm{CBL}$ and $\mathrm{CBL}-\mathrm{G} 2$ dendrimer.

Abbreviations: CBL, chlorambucil; XTT, 2,3-bis-(2-methoxy-4-nitro-5-sulfophenyl)$2 \mathrm{H}$-tetrazolium-5-carboxanilide.

(N/C) ratio in the three groups (Figure 14). Hyperchromatic, irregular border nuclei, and mitotic activity were observed in all the groups. Necrosis in CBL-G2 dendrimer was measured at $20 \%$, while it was evaluated at $60 \%$ in both CBL and control groups. Apoptosis analysis showed that the mitotic and apoptosis counts in CBL-G2 dendrimer were higher than the CBL and the control groups (Figure 15). The results of this study showed that structural abnormalities and anaplasia (a feature of malignancy) were reduced in the CBL-G2 dendrimer conjugate compared with the control group and CBL alone (Figure 16). Nuclear dispolarity and the N/C ratio were observed in all the groups, but epithelial stratification was not observed per high-power field.

\section{Discussion}

Dendrimers have the potential of trapping different molecules within their branches, to safeguard them from environmental influences, and to controllably release them into targeted positions. They also increase the solubility of drugs by trapping them and enhancing their stability. ${ }^{14}$

Dendrimers can carry molecules on their surface by interacting with functional groups; a property that enables specific cells or tissue to be targeted. Clinical uses of these anticancer drugs were restricted by the poor water solubility of the drugs. ${ }^{15}$ Decreasing the drug dosage using dendrimers may result in less drug resistance and fewer drug side effects.

Since dendrimers range between $1 \mathrm{~nm}$ and $10 \mathrm{~nm}$ in size, they can diffuse across the vascular endothelium, enter cells, and then be purified by the kidneys. This characteristic reduces the long-term toxicity and eliminates the demand for a biodegradable plan. ${ }^{16}$ Dendrimers have the capacity to make chemical drugs more stable and increase cellular uptake via functional end groups. Dendrimers afforded significant suppression of HIV in infected cells through being conjugated with genes and being transfered into target cells. ${ }^{17}$ 
In this study, a carboxyl-terminated G2 anionic linearglobular dendrimer was used for the conjugation of CBL. $\mathrm{CBL}-\mathrm{G} 2$ dendrimer conjugate consisting of $\mathrm{CBL}$ was covalently bonded to the outer groups of the dendrimer via ester bonds (Figure 17).

It was proven that the covalent dendrimers were more suitable than the noncovalent dendrimers particularly for targeted drug delivery in favor of the release of kinetic properties. ${ }^{18}$

The nature of the peripheral functional groups of the drug and the scaffolds that link them regulate how the drug is liberated from a conjugate. For drug liberation, ester and amide linkages split via enzymes or under hydrolytic conditions.
It has been demonstrated that ester cleavage is more efficient than amide for drug release. ${ }^{19}$

CBL has two chlorine atoms that make it lethal to cancer. In fact, these atoms attack the DNA of cells and destroy them by alkylation process. Therefore, to protect and preserve this property, G2 anionic linear-globular dendrimer was connected via citric acid to $\mathrm{CBL}$ from the carboxyl end. The ester bond formed as seen in the CBL-G2 dendrimer conjugate confers water solubility property on CBL.

Having covalent attachment between anticancer drugs and conjugated dendrimer via functional groups existing on their surface enables drugs to overcome poor control over drug release rate and noticeably lessen drug release from

A File: $130 \mu$ Date: 25-02-2015 Time: 15:21:06 Particles: 17,255 Acq-time: 140 seconds partec PAS
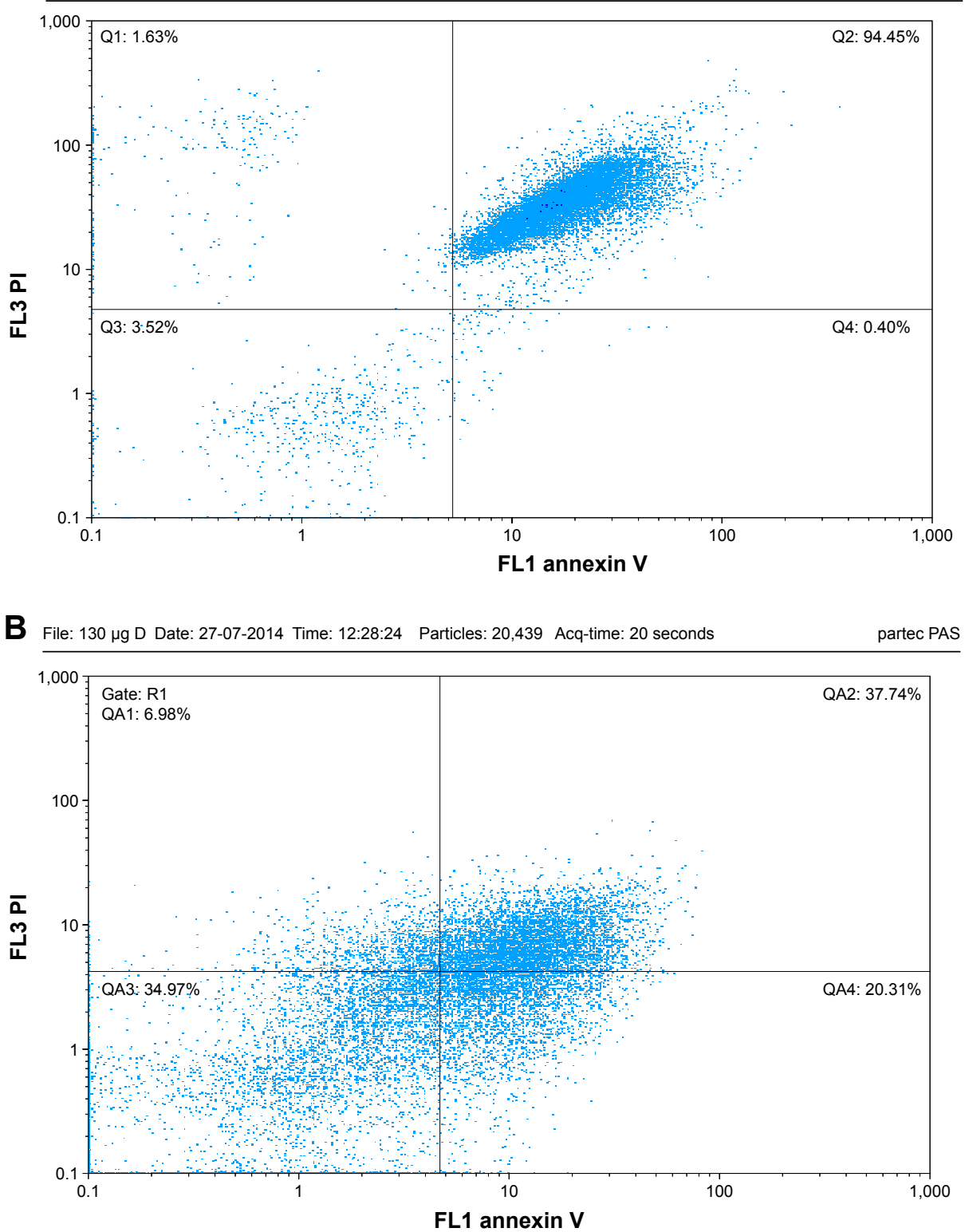

Figure 10 (Continued) 


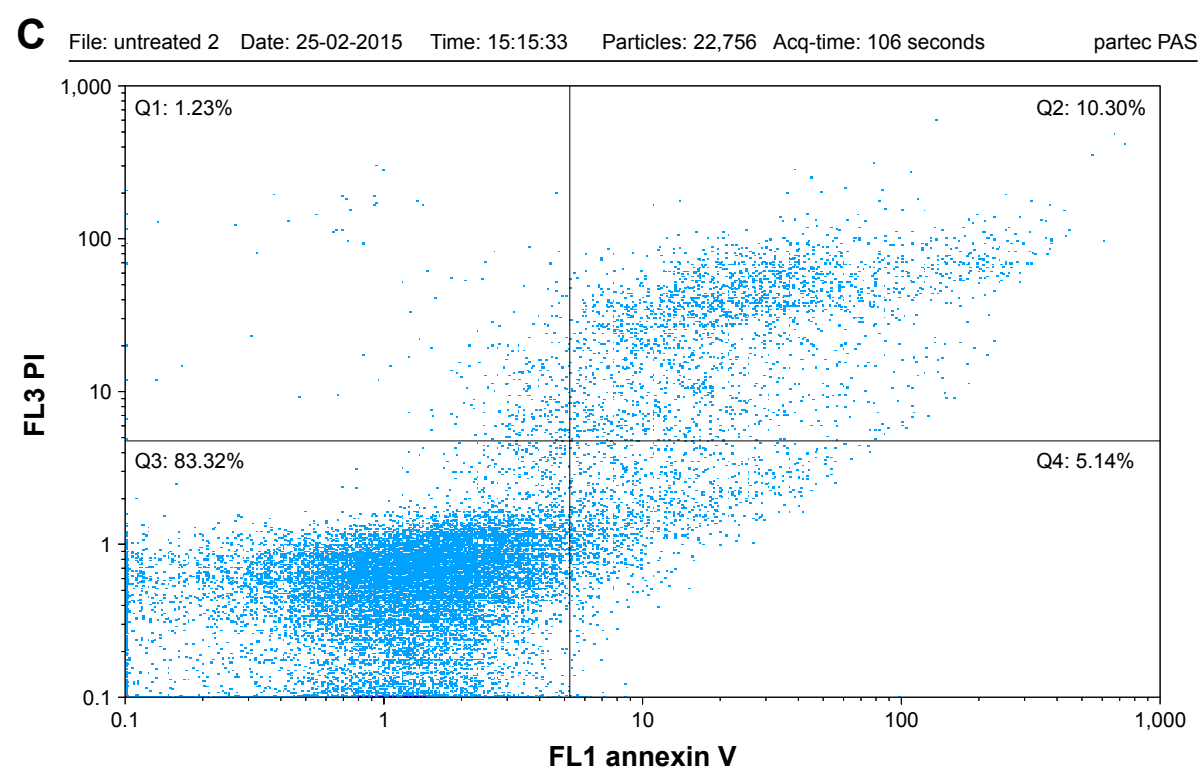

Figure 10 Dot plots of Annexin V-propidium iodide staining are shown in (A) MCF-7 cells treated with I30 $\mu$ g/mL G2 dendrimer-CBL; (B) MCF-7 cells treated with $130 \mu \mathrm{g} / \mathrm{mL}$ CBL; and (C) untreated MCF-7 cells.

Abbreviations: Acq, acquired; CBL, chlorambucil; FL, fluorescence; PI, propidium iodide.

an initial rupture. On the other hand, a linkage between dendrimer-carrying drug and tumor-targeting ligands leads to gathering of the dendrimer carriers in solid tumors with a high drug load to increase the uptake of chemotherapeutic drugs by malignant cells. The fact that there is a direct proportional link between the minimization of plasma concentrations of free drug (reducing systemic toxicity) and maximization of delivery of the drug inward in solid tumors promotes the chemotherapeutic effect of the drug. ${ }^{20}$

No toxicity was observed for the anionic linear-globular dendrimer up to the concentration level of $0.5 \mathrm{mg} / \mathrm{mL}$ compared with the negative control (a cellular growth of $~ 108 \%$ was seen at this concentration). ${ }^{21}$

This study has shown that anionic linear-globular dendrimer with surface carboxylate functional groups conjugated to the outer surface of $\mathrm{CBL}$ contributes

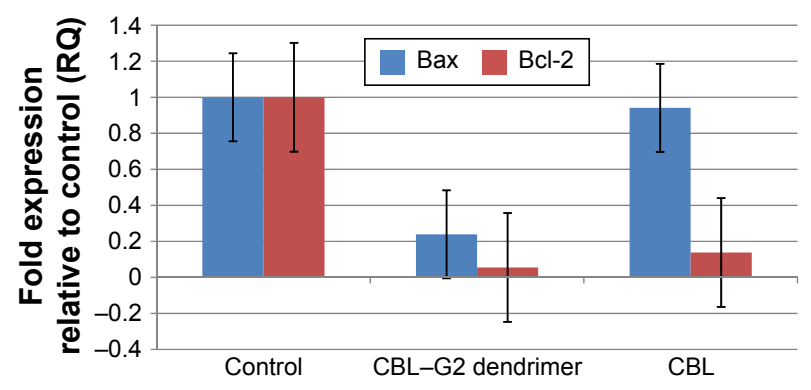

Figure II The effect of $\mathrm{CBL}$ and $\mathrm{CBL}-\mathrm{G} 2$ dendrimer on $\mathrm{Bax}$ and $\mathrm{Bcl}-2$ gene expression.

Abbreviations: $\mathrm{CBL}$, chlorambucil; RQ, relative quantification. significantly improved treatment efficacy over clinical CBL. In this study, a relevant viability test (XTT) was applied to assess the cytotoxic effect of CBL-G2 dendrimer conjugate on MCF-7 cells. Outcomes of this study demonstrated that $\mathrm{CBL}-\mathrm{G} 2$ dendrimer conjugates have dose-dependent antitumor activity. Cells in lysosomal enzymes cleave CBL and the dendrimer's linkage, resulting in an increase in drug release.

The enhanced cytotoxic effect of CBL-G2 dendrimer complexes could be because of the more significant uptake of the conjugates in contrast to free $\mathrm{CBL}$ owing to the citric acid existing on the outer surface of the conjugates. ${ }^{22}$ It is a well-established fact that tumor cells can significantly regulate glucose consumption upward to meet the high-energy demands for cell survival and proliferation. Citric acid is consumed and then regenerated by a sequence of reactions that complete the Krebs cycle with the production of energy. Thus, it could be inferred that cancerous cells need the uptake of CBL-G2 dendrimer more than the normal cells.

Anionic linear-globular dendrimers (G2) are negatively charged nanoparticles, but surprisingly $\mathrm{CBL}-\mathrm{G} 2$ dendrimer conjugate was not repelled by cell membranes that had large negatively charged domains.

It has been proven that the cell membrane is negatively charged; however, cells can take up unfavorable negatively charged particles. Cho et al recently studied the character of surface charges in the internalization of gold nanoparticles. ${ }^{23}$ In fact, such particles can be internalized 


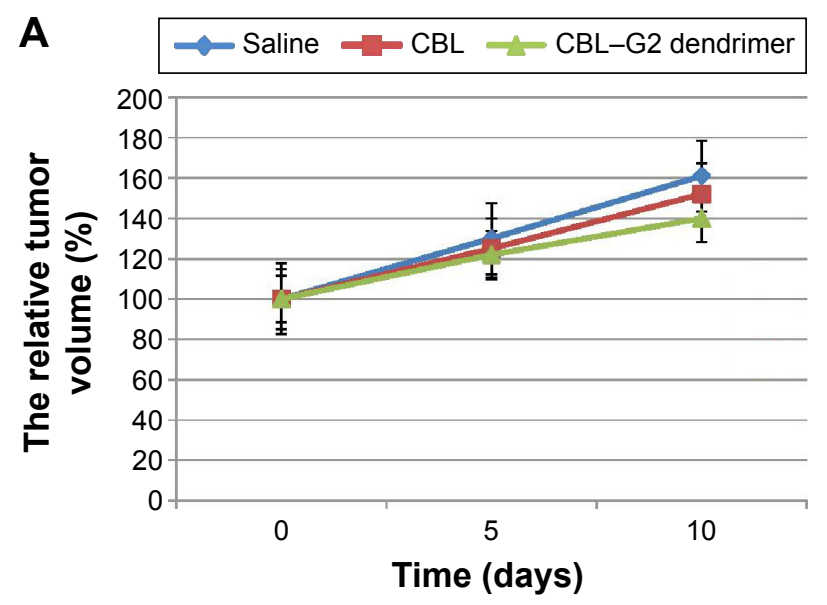

B

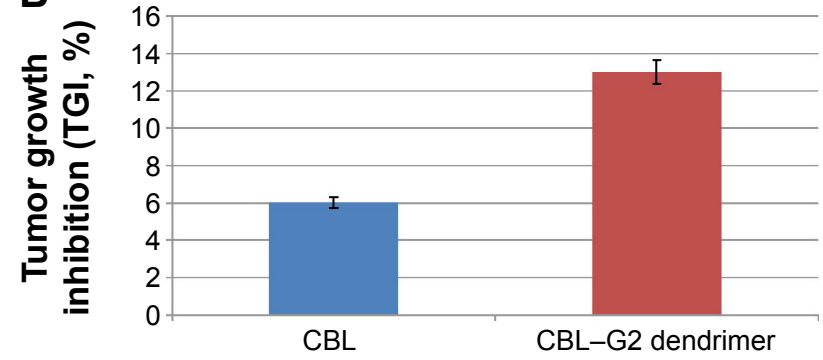

Figure 12 Quantitative analysis of tumor volume and tumor growth inhibition after treatments with $\mathrm{CBL}$ and $\mathrm{CBL}-\mathrm{G} 2$ dendrimer.

Notes: (A and B) Comparison of in vivo tumor inhibition effect of CBL-G2 dendrimer vs CBL alone and saline (as a control group) in the murine 4TI mammary tumor cells $(n=5)$.

Abbreviations: CBL, chlorambucil; TGl, tumor growth inhibition.

into cells without extra energy because of their small size and less aggregation. ${ }^{23}$

Experiments carried out in this study using annexin V-fluorescein isothiocyanate and the recognition of apoptosis revealed that $\mathrm{CBL}-\mathrm{G} 2$ dendrimer hindered the growth of MCF-7 tumor cells by increasing the number of apoptotic

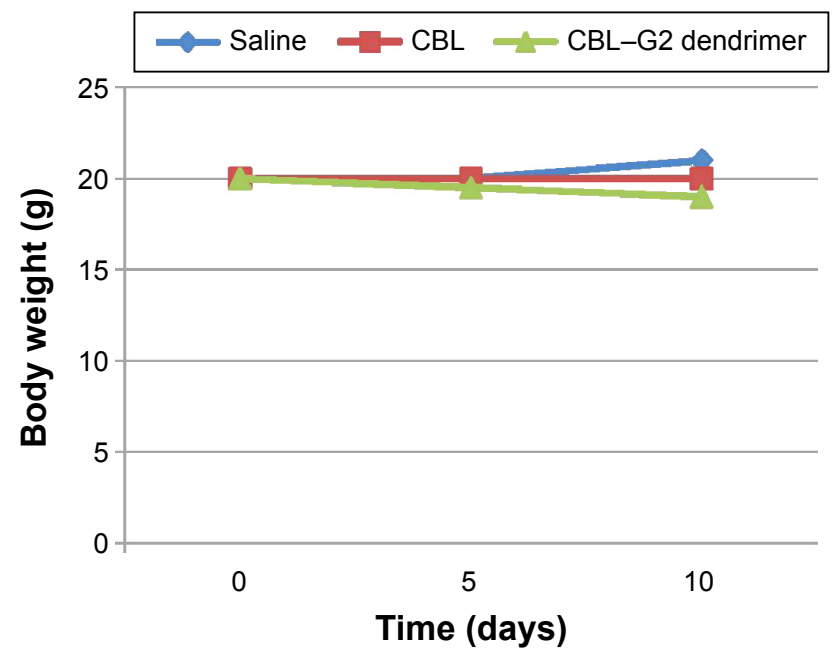

Figure 13 Body weight curves of mice that received different treatments in the study.

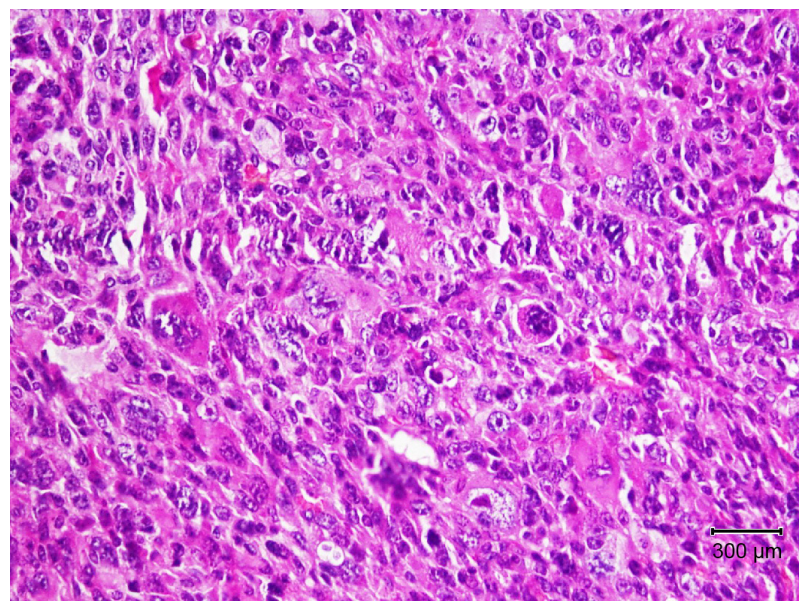

Figure I4 The histological features of tumor with giant cells and high N/C ratio (H\&E, 40X) in the group treated with CBL.

Abbreviations: $\mathrm{CBL}$, chlorambucil; H\&E, hematoxylin and eosin; N/C, nuclear/ cytoplasmic.

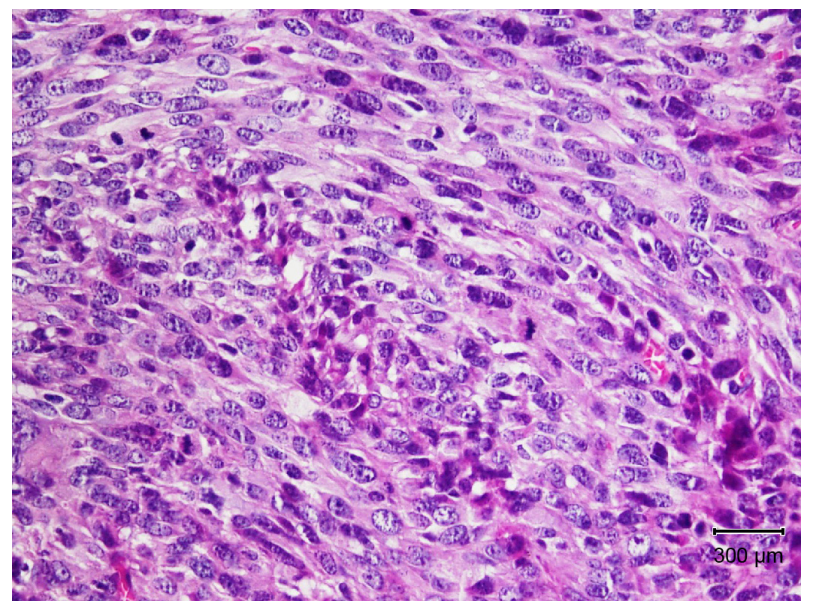

Figure 15 The histological features of tumor with interlacing fascicles and numerous mitotic cells (H\&E, 40X) in the group treated with CBL-G2 dendrimer.

Abbreviations: $\mathrm{CBL}$, chlorambucil; H\&E, hematoxylin and eosin.

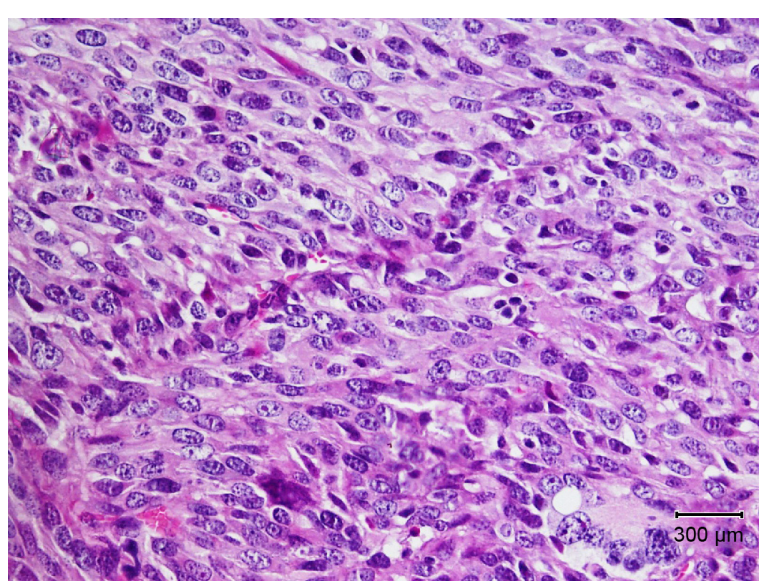

Figure 16 The histological features of tumor, marked anaplasia, and conspicuous nucleoli (H\&E, 40X) in the untreated group.

Abbreviation: $\mathrm{H} \& E$, hematoxylin and eosin. 


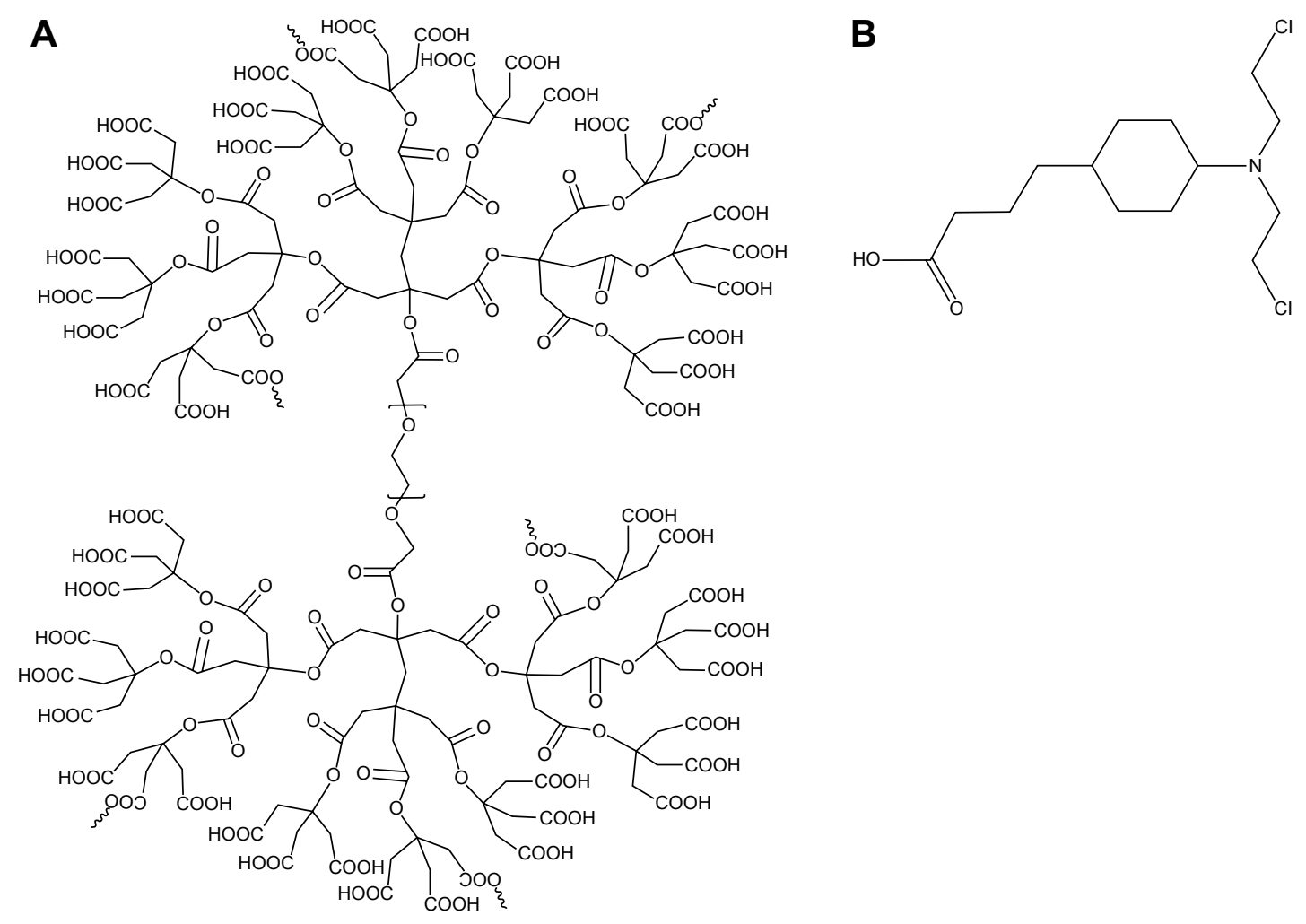

Figure 17 Chemical structure of anionic linear-globular dendrimer CBL-G2 dendrimer conjugate $(\mathbf{A})$ in which the $G 2$ is conjugated to the CBL from the exterior through an ester linkage (B).

Abbreviations: $\mathrm{CBL}$, chlorambucil; H\&E, hematoxylin and eosin.

and necrotic cells. The nanopolymeric CBL reduced the antiapoptotic Bcl-2 expression and the Bcl-2/Bax ratio compared with the control and CBL groups. Therefore, these effects could be attributed to an increased sensitivity of the MCF-7 cells to induce apoptosis when exposed to CBL-G2 dendrimer conjugates.

Results of the current study showed that structural abnormalities, anaplasia, and necrosis were reduced in CBL-G2 conjugate compared with the control group and $\mathrm{CBL}$ alone.

A toxicity study was carried out on murine 4T1 mammary tumor cells with $\mathrm{CBL}$ and $\mathrm{CBL}-\mathrm{G} 2$ dendrimer. Neither mortality nor perceptible body weight loss was seen in the mice treated with $\mathrm{CBL}-\mathrm{G} 2$ dendrimer and free $\mathrm{CBL}$ compared with the untreated control. Blood samples of each group were collected to measure the physiological condition. The results indicated no noticeable side effects among groups which may relate to low-dose of the used CBL. However, further detailed and careful examinations necessitate the study of any potential near-term or long-term side effects of CBL-G2 dendrimer. Branched covalent attachment of G2 via similar ester bond as in CBL-G2 dendrimer conjugates confers water solubility property on CBL. The achievement of tumor growth suppression by $\mathrm{CBL}-\mathrm{G} 2$ dendrimer was used to affirm and guarantee G2 drug delivery as an effective cancer treatment method with low side effects. G2 showed no side effects at all over the suppression of tumor growth at least in mouse models. G2 has the capacity to conjugate with multiple types of water-insoluble anticancer drugs used in chemotherapy. ${ }^{15}$

\section{Conclusion}

Although attempts have been made in the past decade to create nanoparticles for the improvement of drug delivery, few formulations have reached clinical acceptance because of the poor biocompatible attributes of these carrier molecules, such as insolubility, immunogenicity, and low tissue permeability. ${ }^{24}$

G2 anionic linear-globular dendrimer met the three important criteria to qualify for the deliberation of the FDA, ie, biocompatible, biodegradable, and completely amenable to elimination.

Until now, there are only a few studies of how $\mathrm{G} 2$ anionic linear-globular dendrimers have been able to induce apoptosis. It has been proved that G2 anionic linear-globular dendrimers are able to activate apoptosis in MCF-7 and in murine 4T1 mammary tumor cells. 
In addition, this is the first time that $\mathrm{G} 2$ anionic linearglobular dendrimers were successfully used as drug delivery applications to achieve in vivo tumor treatment efficacy. This achievement requires more investigation on biomedical features of anionic globular dendrimer and potential benefits of converting this knowledge into clinical practice in the future. Dendrimers, as polymer-based delivery vehicles, are a good fit to reach the goal of an anticancer drug delivery system, which includes prolonged, localized, targeted, and protected drug interaction with the tumor tissue.

\section{Acknowledgments}

The authors wish to thank the staff of Tehran University of Medical Sciences and Department of Hepatitis and AIDs, Pasteur Institute of Iran, who helped us to do this research.

\section{Disclosure}

The authors report no conflicts of interest in this work.

\section{References}

1. Nazarov AA, Meier SM, Zava O, et al. Protein ruthenation and DNA alkylation: chlorambucil-functionalized RAPTA complexes and their anticancer activity. Dalton Trans. 2015;44(8):3614-3623.

2. San Miguel V, Limer AJ, Haddleton DM, Catalina F, Peinado C. Biodegradable and thermoresponsive micelles of triblock copolymers based on 2-(N,N-dimethylamino)ethyl methacrylate and epsiloncaprolactone for controlled drug delivery. Eur Polym J. 2008;44: 3853-3863.

3. Omoomi FD. Molecular chlorambucil-methionine conjugate: novel anti-cancer agent against breast MCF-7 cell model. J Cancer Sci Ther. 2013;5:75-84.

4. Ooya T, Lee J, Park K. Effects of ethylene glycol-based graft, starshaped, and dendritic polymers on solubilization and controlled release of paclitaxel. J Control Release. 2003;93(2):121-127.

5. Cheng Y, Tongwen X. Dendrimers as potential drug carriers. Part I. Solubilization of non-steroidal anti-inflammatory drugs presence of polyamidoamine dendrimers. Eur J Med Chem. 2005;40(11): 1188-1192.

6. Bhadra D, Bhadra S, Jain S, Jain NK. A PEGylated dendritic nanoparticulate carrier of fluorouracil. Int J Pharm. 2003;257(1-2): $111-124$.

7. Knop K, Hoogenboom R, Fischer D, Schubert US. Poly(ethylene glycol) in drug delivery: pros and cons as well as potential alternatives. Angew Chem Int Ed Engl. 2010;49(36):6288-6308.

8. Namazi H, Adeli M. Dendrimers of citric acid and poly (ethylene glycol) as the new drug-delivery agents. Biomaterials. 2005;26(10): 1175-1183.

OncoTargets and Therapy

\section{Publish your work in this journal}

OncoTargets and Therapy is an international, peer-reviewed, open access journal focusing on the pathological basis of all cancers, potential targets for therapy and treatment protocols employed to improve the management of cancer patients. The journal also focuses on the impact of management programs and new therapeutic agents and protocols on
9. Bielawski K, Bielawska A, Muszynska A, Poplawska B, Czarnomysy R. Cytotoxic activity of G3 PAMAM-NH2 dendrimer-chlorambucil conjugate in human breast cancer cells. Environ Toxicol Pharmacol. 2011;32(3):364-372.

10. Shafiee Ardestani M, Salehi Fordoei A, Abdoli A, et al. Nanosilver based anionic linear globular dendrimer with a special significant antiretroviral activity. J Mater Sci Mater Med. 2015;26(5):179.

11. You S, Zuo L, Li W. Optimizing the time of doxil injection to increase the drug retention in transplanted murine mammary tumors. Int $J$ Nanomedicine. 2010;5:221-229.

12. Zhang C, Pan D, Luo K, et al. Dendrimer-doxorubicin conjugate as enzyme-sensitive and polymeric nanoscale drug delivery vehicle for ovarian cancer therapy. Polym Chem. 2014;5(18):5227-5235.

13. Alizadeh AM, Khaniki M, Azizian S, Mohaghgheghi MA, Sadeghizadeh M, Najafi F. Chemoprevention of azoxymethane-initiated colon cancer in rat by using a novel polymeric nanocarrier-curcumin. Eur J Pharmacol. 2012;689(1-3):226-232.

14. Namazi H, Toomari Hamrahloo Y. Novel PH sensitive nanocarrier agents based on citric acid dendrimers containing conjugated B-cyclodextrins. Adv Pharm Bull. 2011;1(1):40-47.

15. Liu Z, Chen K, Davis C, et al. Drug delivery with carbon nanotubes for in vivo cancer treatment. Cancer Res. 2008;68(16):6652-6660.

16. McNerny DQ, Leroueil PR, Baker JR. Understanding specific and nonspecific toxicities: a requirement for the development of dendrimerbased pharmaceuticals. Wiley Interdiscip Rev Nanomed Nanobiotechnol. 2010;2(3):249-259.

17. Peng J, Wu Z, Qi X, Chen Y, Li X. Dendrimers as potential therapeutic tools in HIV inhibition. Molecules. 2013;18(7):7912-7929.

18. Patri AK, Kukowska-Latallo J, Baker JR Jr. Targeted drug delivery with dendrimers: comparison of the release kinetics of covalently conjugated drug and non-covalent drug inclusion complex. Adv Drug Deliv Rev. 2005;57(15):2203-2214.

19. Menjoge AR, Kannan RM, Tomalia DA. Dendrimer-based drug and imaging conjugates: design considerations for nanomedical applications. Drug Discov Today. 2010;15(5-6):171-185.

20. Kaminskas LM, McLeod VM, Porter CJ, Boyd BJ. Association of chemotherapeutic drugs with dendrimer nanocarriers: an assessment of the merits of covalent conjugation compared to noncovalent encapsulation. Mol Pharm. 2012;9(3):355-373.

21. Alavidjeh MS, Haririan I, Khorramizadeh MR, Ghane ZZ, Ardestani MS, Namazi H. Anionic linear-globular dendrimers: biocompatible hybrid materials with potential uses in nanomedicine. J Mater Sci Mater Med. 2010;21(4):1121-1133.

22. Haririan I, Alavidjeh MS, Khorramizadeh MR, Ardestani MS, Ghane ZZ, Namazi H. Anionic linear-globular dendrimer-cis-platinum (II) conjugates promote cytotoxicity in vitro against different cancer cell lines. Int J Nanomedicine. 2010;5:63-75.

23. Verma A, Stellacci F. Effect of surface properties on nanoparticle-cell interactions. Small. 2010;6(1):12-21.

24. Thomas TP, Patri AK, Myc A, et al. In vitro targeting of synthesized antibody-conjugated dendrimer nanoparticles. Biomacromolecules. 2004;5(6):2269-2274. patient perspectives such as quality of life, adherence and satisfaction. The manuscript management system is completely online and includes a very quick and fair peer-review system, which is all easy to use. Visit http://www.dovepress.com/testimonials.php to read real quotes from published authors. 